\title{
DENATURING GRADIENT GEL ELECTROPHORESIS - A TOOL FOR PLANT PROTECTION RESEARCH
}

\author{
M. O'CALLAGHAN ${ }^{1}$, E.M. GERARD ${ }^{1}$, G.H.J. HEILIG², H. ZHANG', \\ T.A. JACKSON ${ }^{1}$ and T.R. GLARE ${ }^{1}$ \\ ${ }^{1}$ Biocontrol and Biosecurity Group, AgResearch, PO Box 60, Lincoln \\ ${ }^{2}$ Department of Agrotechnology and Food Sciences, Wageningen University, \\ The Netherlands
}

Corresponding author: maureen.ocallaghan@agresearch.co.nz

\begin{abstract}
Analysis of microbial communities associated with plants, insects and soil has been a significant challenge for plant protection researchers, because of the lack of techniques with which to access these populations. A new molecular community profiling technique, $16 \mathrm{~S}$ rRNA gene-based PCR followed by denaturing gradient gel electrophoresis (DGGE), has been used to analyse microbial communities in a number of environments and has many potential uses in plant protection research. The technique is currently being used for the analysis of insect gut microflora, characterisation of phylloplane and rhizosphere microbial populations, and in environmental assessment of the effects of biopesticides and new technologies on indigenous soil microbes.

Keywords: DGGE, microbial community, rhizosphere, insect gut, environmental impact assessment.
\end{abstract}

\section{INTRODUCTION}

Microbial communities in the environment have traditionally been studied by conventional methods based on cultivation of populations, by measurement of their metabolic activities or direct observation using microscopic methods. However, it has long been known that more than $90 \%$ of micro-organisms existing in nature are not amenable to currently available cultural methods (Ward et al. 1990). To overcome these limitations, attention has been focussed on molecular biological techniques, with their powerful ability to access information about microbial communities in their natural habitats. Molecular approaches have mostly been based on sequence determinations of the $16 \mathrm{~S}$ ribosomal RNA (rRNA) genes amplified and cloned from DNA extracted from environmental samples. While this technique provided information about the wealth of as yet unknown bacterial types in nature, it did not allow a full analysis of the microbial diversity within the habitat studied.

The use of highly variable regions of the 16S rRNA gene as molecular indicators for microbial populations in environmental samples in an electrophoretic approach was developed by Muyzer et al. (1993). The electrophoretic technique used most often has been denaturing gradient gel electrophoresis (DGGE). Originally used in the fields of medicine and diagnostic research to detect point mutations, the technique has become a powerful and popular method for the analysis of microbial communities. Coupled with polymerase chain reaction (PCR) and primers that target conserved, taxonomically significant genes, it is a technique that allows the comparison and analysis of total microbial populations.

PCR combined with DGGE analysis of microbial communities is being used in a number of projects carried out by the Biocontrol and Biosecurity Group at Lincoln. These projects include analysis of the gut microflora of several insect pest species, analysis of phylloplane and rhizosphere populations associated with different plant lines, and assessment of the impact of biopesticides and new technologies on the natural soil 
microflora. These applications are discussed further in the following sections.

\section{DGGE - HOW IT WORKS}

The steps involved in DGGE are briefly explained here and are outlined in Figure 1. More detailed technical information about DGGE can be found in other publications (e.g. Heuer \& Smalla 1997; Gelsomino et al. 1999; Heuer et al. 2001).

The application of DGGE to study microbial populations is a multi-step procedure relying on several other techniques. Firstly, DNA is extracted from the environmental sample (for example, soil, plant tissue or insect gut). The efficient, routine extraction of total DNA from environments such as soil is a relatively recent development, but this step is critical, as the DNA recovered must be representative of the habitat sampled (see Limitations section). The second technique is polymerase chain reaction (PCR), which allows the specific amplification of a segment of DNA around 1 billion times the original concentration (Mullis et al. 1994). After the total microbial DNA is extracted from the sample, the bacterial 16S rRNA genes are amplified by PCR with universal primers. The double stranded PCR products are then subjected to DGGE.



\section{FIGURE 1: Steps in denaturing gradient gel electrophoresis (DGGE) for analysis of microbial populations.}

DGGE enables PCR amplification products of the same length but with different internal sequence composition to be separated in gradient gels according to the melting behaviour of the DNA. In traditional electrophoresis, DNA fragments are separated on the basis of size as they move through the gel. In DGGE, the gels contain a linearly increasing gradient of denaturing chemicals (formamide and urea). As the double stranded DNA fragments begin to move through the gel, they reach higher levels of denaturing chemicals and begin to melt at a point in the gel that is determined by the sequence of the fragment, which is different for different species. Branching of the molecule then sharply decreases the mobility of the fragment through the gel. To stabilise the melting behaviour of the DNA fragments and to ensure that they do not denature completely during electrophoresis, a GC clamp, consisting of a long stretch of mostly G/C base pairs is incorporated into one of the primers and subsequently into the PCR products. By this method, a PCR mixture containing numerous species will produce a profile in which each band will consist of a population of identical DNA fragments, and, theoretically, each band will be derived from a single species. This is effectively a community fingerprint (for example, see Figure 3a). The fingerprint can be analysed using software packages (e.g. Diversity Database (BioRad, Hercules, California) and Bionumerics (Applied Maths, Austin, Texas)), and various statistics applied to compare banding patterns between lanes and gels. The results can conveniently be viewed as dendrograms (e.g. see Figure 3b). 
One of the attractive features of this technique is that individual bands can be excised for subsequent sequence determination and sequence comparison with databases. Hence the species present in the community can be identified if similar species are in the database. Alternatively, PCR products from the initial amplification can be cloned into plasmid vectors, run on DGGE and sequenced to determine species.

The scope of the analysis depends on the specificity of the primers used in the PCR. The technique has been used extensively for analysis of PCR products amplified from $16 \mathrm{~S}$ rRNA genes in complex bacterial communities. Subgroups of bacteria can be accessed by using primers designed for particular groups, for example, primers are available for the $\alpha$ - and $\beta$-proteobacteria, as well as various groups of Gram negative bacteria (Gomes et al. 2001). The technique has also been applied to analysis of actinomycetes (Heuer et al. 1997) and fungal populations (van Elsas et al. 2000). In addition, a number of phylogenetic and functional groups of micro-organisms are now accessible using this technique, such as fluorescent pseudomonads (Widmer et al. 1998).

\section{ANALYSIS OF INSECT-ASSOCIATED MICROFLORA}

Invertebrates harbour numerous micro-organisms which have a range of functions. Some bacteria in the insect gut are important in the breakdown of organic material, while others have been implicated in reproduction-related events, such as pheromone production. Interactions between invertebrates and their associated bacteria range from symbiosis to pathogenesis. In some cases, gut bacteria can prevent the growth of insect pathogens, while others are disease-causing. Despite the importance of invertebrate microorganisms to both the invertebrates themselves and the environment, they have not been studied in depth, in part because of the lack of techniques to access these communities. Most studies have examined the gut microflora by isolating and culturing the microbes, but as only a relatively small proportion of bacteria associated with insects can be cultured, more sensitive methods are necessary to understand the role of these bacteria in insectbacteria relationships.

DGGE analysis has been used recently to characterise bacterial communities associated with insects. Reeson et al. (2003) used the technique in a study of the microbial ecology of the gut of the social wasp Vespula germanica, with the eventual aim of developing a novel approach for biological control of this invasive pest. DGGE profiles of larval guts were variable, suggesting that $V$. germanica is not dependent on particular mutualist or symbiotic bacteria for its nutrition. DGGE analysis of Australian wasps led to the discovery of rickettsia associated with the larvae (Reeson et al. 2003). Rickettsia are gram negative, obligate intracellular organisms that can be pathogenic to their host. In New Zealand, a joint Landcare/AgResearch programme has been examining the microflora of Vespula wasps, looking for micro-organisms that could play a role in the biocontrol of these pests. Application of DGGE to wasp gut extracted DNA revealed many bacterial species associated with the wasps. The aim of the study is to identify micro-organisms that can be used as chronic disease vectors for wasp control. Rickettsia are also present in the New Zealand populations of wasp examined $(\mathrm{H}$. Heilig \& $\mathrm{T}$. Glare, unpubl. data).

The microbial ecology of the alimentary tract of the New Zealand grass grub, Costelytra zealandica, is currently being studied at AgResearch Lincoln, using a combination of techniques, including DGGE. The alimentary tract consists, principally, of a large midgut and a modified hindgut, known as the fermentation sac, which contains a large number of micro-organisms. The ability of scarab larvae to develop on low energy organic substrates suggests that some of these microbes could be specialised symbionts. However, to determine which microbes are symbionts has proven impossible by conventional microbiological methods due to the diverse mixture of microbes containing many nonculturable species. Preliminary DGGE analysis (Fig. 2) shows that around $30 \%$ of bands in the hindgut (roughly corresponding to number of species - see limitations section below) were common to different larvae, while in the midgut only $13 \%$ of bands were shared, suggesting greater specificity of the hindgut flora. Comparison of microbial 
community profiles made directly from guts and profiles of bacteria cultured from guts indicates that most hindgut bacteria are non-culturable (52\%), a greater proportion than non-culturable organisms in the midgut (31\%). These results support the hypothesis that the hindgut is the most likely location of potential symbionts of the grass grub larva.



FIGURE 2: DGGE gel of 16s rDNA amplification products from total DNA extracted from the grass grub larval midgut (MG, Lane 3) and hindgut (HG, Lane 4). Lanes 1 and 2 contain amplification products from total DNA extracted from microbes cultured from the midgut on Luria Bertani agar (LB) and nutrient agar (NA) respectively. Lanes 5 and 6 contain amplification products from DNA extracted from microbes cultured from the hindgut on NA and LB respectively.

\footnotetext{
ANALYSIS OF PLANT-ASSOCIATED AND SOIL MICROFLORA

PCR and DGGE have been used to analyse the natural bacterial communities associated with plants and have led to improved understanding of the relationships between plants and soil micro-organisms. Smalla et al. (2001) demonstrated a rhizosphere effect - the increased abundance of some bacterial populations in the vicinity of the roots of three types of plant. A plant dependent diversity of the bacterial patterns was shown at several sampling times. Marschner et al. (2002) used the technique to examine the spatial and temporal dynamics of the microbial community structure in the rhizosphere of white lupin. They found that community structure changed with root age, and bacterial and fungal populations responded to different organic acids in plant exudates.

While the majority of studies conducted to date have focussed on bacterial populations, some groups have been using the technique to examine fungal populations associated with plants. Kowalchuk et al. (1997) used nested PCR and DGGE analysis to characterise fungal populations in plant roots in an effort to identify fungi causing degeneracy in marram stands. DGGE patterns from laboratory-grown plants showed that this technique could reliably identify known plant-infecting fungi. Smit et al. (1999) developed primer sets that enabled the detection of all major fungal taxa except yeasts in wheat rhizosphere soil samples, while Borneman \& Hartin (2000) used PCR amplification of fungal rRNA genes in the analysis of so called "disease suppressive soils". Genetic differences were
} 
found in the fungal communities present in avocado grove soils which were considered to be either suppressive or conducive to infections by Phytophthora cinnamoni. This molecular approach provided a markedly different depiction of the soil fungal community than that generated by a culture-based analysis, confirming the value of rDNA-based approaches.

\section{ASSESSING NON-TARGET IMPACTS OF NEW TECHNOLOGIES}

DGGE has been used in biosafety research to assess the impact of biocontrol agents and transgenic plants on microbial community composition. For example, Heuer et al. (2002) examined the effect of genetically modified (T4 lysozyme-expressing) potato plant roots on bacterial rhizosphere communities. The study showed that environmental factors related to season, field site or year, but not to the T4 lysozyme expression of the transgenic plants, influenced the rhizosphere communities. Lottman et al. (2000) used the technique to monitor the effect of introduction of a biocontrol strain of Serratia grimesii (which was antagonistic to the fungal plant pathogen Verticillium sp.) on the indigenous rhizosphere populations on potatoes. At all sampling times, the DGGE pattern of root and tuber communities did not show differences between the inoculated and non-inoculated potatoes.

DGGE is also being used to assess the impact of transgenic plants on indigenous soiland plant-associated bacteria in New Zealand. Potatoes modified to express the antimicrobial peptide, magainin, have been developed at Crop \& Food Research, Lincoln, with the aim of protecting the tubers from the soft rot pathogen Erwinia carotovora (Barrell 2001). In a preliminary study, culturable bacterial and fungal populations on the leaves, roots and tubers from the various plant lines (including the parental control lines and an unrelated cultivar) grown in a small scale field trial have been enumerated (O'Callaghan et al. 2003). These bacterial populations are currently being characterised using DGGE. Results to date suggest that there is little difference in overall bacterial species composition associated with transgenic (magainin-expressing plants) compared to non-transgenic parental lines (Fig. 3). UPMAGA (unweighted pair group method using arithmetic averages) comparison of banding patterns (e.g. Fig. 3b) showed some clumping of transgenic or non-transgenic samples, but in all cases subgroupings contained at least one sample from each treatment. Comparisons over a number of replicate studies have not shown any consistent impact of magainin-producing potatoes on soil bacterial species composition.

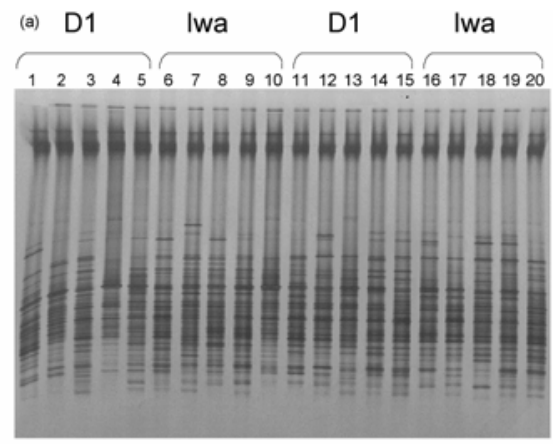

(b)

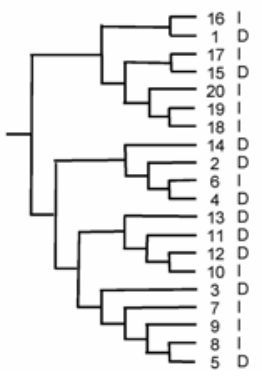

FIGURE 3: (a) DGGE gel of 16s rDNA amplification products from total DNA extracted from tuber surfaces of transgenic (D1) and non-transgenic parental control line (Iwa) potatoes (amplification of alphaproteobacteria). (b) Analysis of band similarity between lanes on 3a using UPGAMA and Jaccard Coefficient, unweighted for band intensity (Diversity Database software, BioRad). 
Analysis of 16s rRNA gene fingerprints by DGGE has also been used in studies examining the non-target effects of chemical herbicides and pesticides. El Fantroussi et al. (1999) reported the effects of long term application of phenylurea herbicides on soil microbial communities. Microbial community structures were significantly different in treated and untreated soils, with bacterial diversity lower in treated soils. The most affected species in soils treated with diuron and linuron belonged to an uncultivated bacterial group, a difference that would not have been detected using traditional methods based on culturing. A similar technique was used to examine the effect of chemical pesticides on bacterial communities in soil (Engelen et al. 1998). Distinct and highly reproducible community patterns (or fingerprints) resulted from application of the different pesticides, indicating that the structural composition of the bacterial community was altered by the application of pesticides.

\section{LIMITATIONS OF DGGE ANALYSIS OF PCR PRODUCTS}

As with any technique used to study microbial communities in the environment, there are limitations to DGGE analysis that need to be taken into account. Some of these limitations are not specific only to this technique but still require consideration. Because analysis of microbial communities is based on extraction of community DNA from environmental samples, it is important that the DNA recovered is representative of the habitat. To achieve this, consideration must be given to several factors, including an appropriate sampling strategy, efficient extraction of cells from the environmental sample and efficient lysis of cells. Previously, lack of efficient techniques for extraction of DNA from soil has limited the analysis of microbial populations in soil but a number of rapid and flexible techniques are now available (e.g. Krsek \& Wellington 1999; Niemi et al. 2001). DNA extraction efficiency with respect to both the quantity and quality of DNA recovered can vary between techniques and soil types as found in a study of New Zealand soils (Lloyd-Jones \& Hunter 2001).

Assuming efficient extraction of DNA which represents the microbial community is achieved, it is important to note that biases may be introduced by the PCR amplification step. These can occur for a number of reasons, for example preferential or selective amplification might occur because of inefficient primer annealing. PCR-introduced biases have been reviewed by Wintzingerode et al. (1997).

There are some limitations that are specific to DGGE analysis of microbial communities. Ideally one species yields one band but in some strains two or more bands have been detected. For example, we have found that Serratia entomophila, a common soil bacterium in New Zealand, has two variants of the 16s gene resulting in two closely migrating bands on DGGE. On the other hand, it has sometimes been observed that closely related or even phylogenetically unrelated strains have similar electrophoretic mobilities, resulting in the band from one species being hidden behind the band of another species. This may lead to an underestimation of the actual diversity in the community. For ecosystems containing large numbers of equally abundant micro-organisms, highly complex banding patterns will be obtained, which can be difficult to interpret.

Another limitation is determination of species by $16 \mathrm{~s}$ sequences alone. The number of 16 s sequences for bacteria has reached over 60,000 (e.g. Cole et al. 2003, Ribosomal Database Project II, http://rdp.cme.msu.edu/html/index.html), but $16 \mathrm{~s}$ is just one method for determining bacterial species and many species are not represented in the databases.

\section{CONCLUSION}

Analysis of microbial communities is a complex task that cannot be achieved by traditional microbial culturing methods. DGGE provides a new technology, allowing for the first time a picture of such communities to be gained. This technique will prove invaluable in unravelling complex and important ecological questions. Microbial communities associated with insects, plants and soil can be analysed on several levels, ranging from community structure of dominant populations using conserved sequence primers, through to phylogenetic sequence analysis of single bands generated by 
individual community members. The advantage of looking at the total DNA is that information can be gained on all constituents of the community, including non-culturable organisms. Non-culturable pathogens can also be detected among diverse communities. The advantage of analysing rDNA is that fingerprints of the most dominant metabolically active species can be obtained. The technique is well developed for bacterial community analysis, but application to other organisms, such as fungi and nematodes, is only in its infancy. In the future, this powerful tool will greatly advance our ecological knowledge of organisms in diverse environments, allowing us to both monitor the fate of applied organisms in specific environments and to determine the effect of new practices and technologies on the existing microbial communities. DGGE has made an impressive entry and promises to become an invaluable tool in future plant protection research.

\section{ACKNOWLEDGEMENTS}

Field trials of transgenic potatoes were conducted by Dr Tony Conner and Jill Reader of Crop \& Food Research. Research on the microbial ecology of the scarab gut is supported by the Marsden Fund.

\section{REFERENCES}

Barrell, P.J. 2001: Expression of synthetic magainin genes in potato. $\mathrm{PhD}$ thesis, Lincoln University, New Zealand. $153 \mathrm{p}$.

Borneman, J.; Hartin, R.J. 2000: PCR primers that amplify rRNA genes from environmental samples. Appl. Environ. Microbiol. 66: 4356-4360.

Cole, J.R.; Chai, B.; Marsh, T.L.; Farris, R.J.; Wang, Q.; Kulam, S.A.; Chandra, S.; McGarrell, D.M.; Schmidt, T.M.; Garrity, G.M.; Tiedje, J.M. 2003: The Ribosomal Database Project (RDP-II): previewing a new autoaligner that allows regular updates and the new prokaryotic taxonomy. Nucleic Acids Res. 31: 442-443.

Engelen, B.; Meinken, K.; Wintzingerode, F.V.; Heuer, H.; Malkomes, H.-P.; Backhaus, H. 1998: Monitoring impact of pesticide treatment on bacterial soil communities by metabolic and genetic fingerprinting in addition to conventional testing procedures. Appl. Environ. Microbiol. 64: 2814-2821.

El Fantroussi, S.; Verschuere, L.; Verstraete, W.; Top, E.M. 1999: Effect of phenylurea herbicides on soil microbial communities estimated by analysis of 16S rRNA gene fingerprints and community-level physiological profiles. Appl. Environ. Microbiol. 65: 982-988.

Gelsomino, A.; Keijzer-Wolters, A.C.; Cacco, G.; van Elsas, J.D. 1999: Assessment of bacterial community structure in soil by polymerase chain reaction and denaturing gradient gel electrophoresis. J. Microbiol. Methods 38: 1-15.

Gomes, N.C.M.C.; Heuer, H.; Schonfeld, J.; Costa, R.; Hagler-Mendonca, R.; Smalla, K. 2001: Bacterial diversity of the rhizosphere of maize (Zea mays) grown in tropical soil studied by temperature gradient gel electrophoresis. Plant and Soil 232: 167-180.

Heuer H.; Smalla, K. 1997: Application of denaturing gradient gel electrophoresis and temperature gradient gel electrophoresis for studying soil microbial communities. In: van Elsas, J.D.; Trevors, J.T.; Wellington, E.M.H. ed. Modern Soil Microbiology. Marcel Dekker, New York. Pp. 353-374.

Heuer, H.; Krsek, M.; Baker, P.; Smalla K.; Wellington, E.M. 1997: Analysis of actinomycete communities by specific amplification of genes encoding $16 \mathrm{~S}$ rRNA and gel-electrophoretic separation in denaturing gradients. Appl. Environ. Microbiol. 63: 3233-3241.

Heuer, H.; Wieland, G.; Schonfeld, J.; Schonwalder A.; Gomes, N.C.M.; Smalla K. 2001: Bacterial community profiling using DGGE or TGGE analysis. In: Rochelle, P.A. ed. Environmental Molecular Biology: Protocols and Applications. Horizon Scientific Press, Wymondham, UK. Pp. 177-190. 
Heuer, H.; Kroppenstedt, R.M.; Lottmann, J.; Berg, G.; Smalla K. 2002: Effects of T4 lysozyme release from transgenic potato roots on bacterial rhizosphere communities are negligible relative to natural factors. Appl. Environ. Microbiol. 68: 1325-1335.

Krsek, M.; Wellington, E.M.H. 1999: Comparison of different methods for the isolation and purification of total community DNA from soil. J. Microbiol. Methods 39: 116

Kowalchuk, G.A.; Gerards S.; Woldendorp, J.W. 1997: Detection and characterisation of fungal infections of Annophila arenaria (marram grass) roots by denaturing gradient gel electrophoresis of specifically amplified $18 \mathrm{~S}$ rDNA. Appl. Environ. Microbiol. 63, 3858-3865.

Lloyd-Jones, G.; Hunter D.W.F. 2001: Comparison of rapid extraction methods applied to contrasting soils. Soil Biol. Biochem. 33: 2053-2059.

Lottmann, J.; Heuer, H.; de Vries, J.; Mahn, A.; During, K.; Wackernagel, W.; Smalla, K.; Berg, G. 2000: Establishment of introduced antagonistic bacteria in the rhizosphere of transgenic potatoes and their effect on the bacterial community. FEMS Microbiol. Ecol. 33: 41-49.

Marschner, P.; Neumann, G.; Kania, A.; Weiskopf, L.; Lieberei, R. 2002: Spatial and temporal dynamics of the microbial community structure in the rhizosphere of cluster roots of white lupin (Lupinus albus L.). Plant and Soil 246: 167-174.

Mullis K.; Ferre F.; Gibbs R. (ed.) 1994: The polymerase chain reaction. Birkhauser Boston Inc., Cambridge, USA. 458 p.

Muyzer G.; de Waal, E.C.; Uitterlinden A.G. 1993: Profiling of complex microbial communities by denaturing gradient gel electrophoresis analysis of polymerase chain reaction-amplified genes coding for $16 \mathrm{~S}$ rRNA. Appl. Environ. Microbiol. 59: 695-700.

Niemi, R.M.; Heiskanen, I.; Wallenius, K.; Lindstrom, K. 2001: Extraction and purification of DNA in rhizosphere soil samples for PCR-DGGE analysis of bacterial consortia. J. Microbiol. Methods 45: 155-165.

O'Callaghan, M.; Gerard, E.M.; Waipara, N.W.; Young, S.D.; Glare, T.R.; Barrell, P.J.; Conner, A.J. 2003: Microbial communities of Solanum tuberosum and magaininproducing transgenic lines. Submitted to Plant and Soil.

Reeson, A.F.; Jankovic, T.; Kasper, M.L.; Rogers, S.; Austin A.D. 2003: Application of 16S rDNA-DGGE to examine the microbial ecology associated with a social wasp Vespula germanica. Insect Molec. Biol. 12: 85-91.

Smalla, K.; Wieland, G.; Buchner, A.; Zock, A.; Parzy, J.; Kaiser, S.; Roskot, N.; Heuer, H.; Berg, G. 2001: Bulk and rhizosphere soil bacterial communities studied by denaturing gradient gel electrophoresis: plant-dependent enrichment and seasonal shifts revealed. Appl. Environ. Microbiol. 67: 4742-4751.

Smit, E.; Leeflang, P.; Glandorf, B.; van Elsas, J.D.; Wernars K. 1999: Analysis of fungal diversity in the wheat rhizosphere by sequencing of cloned PCR-amplified genes encoding 18S rRNA and temperature gradient gel electrophoresis. Appl. Environ. Microbiol. 65: 2614-2621.

van Elsas, J.D.; Duarte, G.F.; Keijzer-Wolters, A.; Smit, E. 2000: Analysis of the dynamics of fungal communities in soil via fungal-specific PCR of soil DNA followed by denaturing gradient gel electrophoresis. J. Microbiol. Methods 43: 133-151.

Ward, D.M.; Weller, R.; Bateson, M.M. 1990: 16S rRNA sequences reveal numerous uncultured microorganisms in the natural community. Nature 344: 63-65.

Widmer, F.; Seidler, R.J.; Gillevet, P.M.; Watrud, L.S.; Di Giovanni G. 1998: A highly selective PCR protocol for detecting 16S rRNA genes of the genus Pseudomonas (sensu stricto) in environmental samples. Appl. Environ. Microbiol. 64: 2545-2553.

Wintzingerode, F. von; Gobel, U.B.; Stackebrandt E. 1997: Determination of microbial diversity in environmental samples: pitfalls of PCR-based rRNA analysis. FEMS Microbiol. Rev. 21: 213-229. 